\title{
BIOPOLÍTICA, MOVIMENTOS SOCIAIS E RECURSOS GENÉTICOS: O CASO DO PAA SEMENTES
}

\author{
BIOPOLITICS, SOCIAL MOVEMENTS AND GENETIC \\ RESOURCES: THE CASE OF PAA SEEDS
}

\author{
BIOPOLITICA, MOVIMIENTOS SOCIALES Y RECURSOS \\ GENÉTICOS: EL CASO DE PAA SEMILLAS
}
Matheus Hoffmann Pfrimer - Universidade Federal de Goiás - Goiânia - Goiás - Brasil matheuspfrimer@hotmail.com

\author{
Estevan Leopoldo de Freitas Coca- Universidade Estadual \\ Paulista-Presidente Prudente - São Paulo - Brasil \\ estevanleopoldo@yahoo.com.br
}

Ricardo César Barbosa Júnior- Universidade Federal de Goiás - Goiânia - Goiás - Brasil
ribarbosajß@gmail.com

\section{Resumo}

Os recursos genéticos são elementos estratégicos no controle e na organização da cadeia produtiva da agricultura capitalista. No Brasil, esse processo não ocorre desprovido de conflitos, já que movimentos sociais do campo resistem à manipulação dos recursos genéticos por meio de ações contestatórias e propositivas. Procurando analisar uma recente política pública brasileira, o Programa de Aquisição de Alimentos - "PAA Sementes", este estudo parte da operacionalização do conceito de fungibilidade do poder, o qual considera que este se expandiu à todas as dimensões da vida. A biopolítica, em um contexto da vida pluripotente, passa a ser exercida em nível intracelular por meio da biotecnologia. Nessa perspectiva, o poder deixa de ser exclusivamente de natureza territorial, passando a ser exercido pela manipulação da temporalidade da vida com 0 intuito de controlar o território. Por meio deste sistema de conceitos buscamos verificar se o "PAA Sementes" pode ser considerado uma forma de reequacionamento de forças em um contencioso biopolítico pelo controle da manipulação dos recursos genéticos, mais precisamente das sementes. A partir das instâncias em litígio entre 0 agronegócio e a agricultura camponesa, verifica-se ao longo do movimento analítico estabelecido que o "PAA Sementes" se apresenta como um mecanismo de reequilíbrio entre esses dois projetos biopolíticos diversos.

Palavras-chave: PAA Sementes, biopolítica, recursos genéticos, movimentos sociais do campo.

\section{Abstract}

Genetic resources are strategic elements for the control and organization of the production chain of capitalist agriculture. In Brazil, this process is not devoid of conflicts, as rural social movements resist the manipulation of genetic resources through contestatory and propositional actions. Seeking to analyze a recent Brazilian public policy, Food Acquisition Program (PAA), which has a new modality -"PAA Seeds",, this study departs from the operationalization of the concept of fungibility of power, which considers that power has expanded to all dimensions of life. Thus, biopolitics in a context of pluripotent life, becomes exercised at the intracellular level through biotechnology. In this perspective, power is no longer exclusively of a territorial nature becoming possible to exercise by the manipulation of the temporality of life in order to control the territory. Through this 
system of concepts, we seek to verify if "PAA Seeds" can be considered a form of reappraising forces in a biopolitical contentious for the control of the manipulation of genetic resources, specifically the seeds. Based on the instances of dispute between agribusiness and peasant agriculture, we identify along the established analytical movement that "PAA Seeds" is presented as a rebalancing mechanism between these two different biopolitical projects.

Key words: PAA Seeds, biopolitics, genetic resources, rural social movements.

\section{Resumen}

Los recursos genéticos son elementos estratégicos en el control y la organización de la cadena productiva de la agricultura capitalista. En Brasil, ese proceso no se produce sin conflictos, ya que los movimientos sociales del campo resisten a la manipulación de recursos genéticos por medio de prácticas contestatarias y propositivas. Buscando analizar una reciente política pública brasileña, el Programa de Adquisición de Alimentos - "PAA Semillas", esta investigación parte de la operacionalización del concepto de fungibilidad del poder, que plantea que el poder se ha expandido a todas las dimensiones de la vida. Por lo tanto, la biopolítica, en un contexto de la vida pluripotente, pasa a ser ejercida a nivel intracelular a través de la biotecnología. En esta perspectiva, el poder ya no es exclusivamente de carácter territorial y se ejerce por la manipulación de la temporalidad de la vida con el fin de controlar el territorio. A través de este sistema de conceptos, tratamos de verificar si el "PAA Semillas" puede ser considerado una forma de ajuste de fuerzas en un litigió biopolítico por el control de la manipulación de los recursos genéticos, más concretamente de las semillas. Desde las instancias en disputa entre el agronegoció y la agricultura campesina, se puede observar durante el movimiento analítico establecido que el "PAA Semillas" se presenta como un mecanismo de reequilibrio entre esos dos proyectos biopolíticos diversos.

Palabras-clave: PAA Semillas, biopolítica, recursos genéticos, movimientos sociales del campo.

Introdução

Sabendo que nenhum país é completamente autossuficiente, os intercâmbios entre as diversas regiões do mundo são importantes em nossa realidade. Diante das leis naturais, a variabilidade genética é um fator fundamental para o fortalecimento e perpetuação da vida. No entanto, em sentido contrário ao que se poderia esperar, o regime de comércio internacional neoliberal tem, ao oposto de promover uma maior troca de recursos genéticos, resultado em uma drástica erosão destes. Para colocar isso em perspectiva, segundo estimativas da Organização das Nações Unidas para a Alimentação e Agricultura (FAO) (1999), entre 1990 e 2000, $75 \%$ dos recursos genéticos foram perdidos.

Todavia, esse movimento tem encontrado resistência por parte dos camponeses que dependem da agrobiodiversidade para a manutenção do seu modo de vida e produção, visto que os recursos genéticos são a base de toda a agricultura. Assim, neste trabalho investigamos a relação entre recursos genéticos e movimentos sociais do campo, identificando que no Brasil o Estado tem sido pressionado por alguns destes movimentos a mitigar esse processo por meio de políticas públicas. O Programa de Aquisição 
de Alimentos (PAA), por exemplo, possui uma nova modalidade - o "PAA Sementes" - que visa resgatar, armazenar e multiplicar sementes e mudas. Este programa, que é inovador ao reduzir as desigualdades rurais, criando um mercado institucional para agricultores camponeses e ao mesmo tempo contribuindo com a segurança alimentar da população rural e urbana (De Schutter, 2014; FAO, 2015), evoluiu ao incorporar essa nova preocupação. Dessa forma, exploramos a referida questão, compreendendo que enquanto o PAA tem sido amplamente estudado, a literatura acadêmica que versa a respeito dessa nova modalidade ainda é incipiente.

A reflexão a seguir se caracteriza essencialmente como um estudo de caso que visa verificar a partir do contexto do "PAA Sementes" se o fulcro das tensões entre o Estado e movimentos sociais do campo teria incorporado uma nova dimensão além da questão fundiária, a instar o exercício do poder por meio do controle dos recursos genéticos. Apresenta-se ainda como questão secundária, aos propósitos da premissa geral, verificar se a concepção foucaultiana do biopoder teria se transladado da escala da espécie para a escala instracelular enquanto mecanismo de controle sobre os corpos, dando início ao que Rose (2007) denominou de era molecular.

Essa expansão do poder da dimensão territorial (questão fundiária) para a dimensão da vida (recursos genéticos), segundo Braun (2007), implica na asserção no campo teórico de que a biopolítica e a geopolítica nada mais são do que faces diferentes de uma mesma moeda: o poder fungível. Esse sistema conceitual pretende compreender a expansão da política a todas as dimensões da vida a partir da instrumentalização das técnicas de biotecnologia. Dessa forma, o estudo procura operacionalizar esse sistema conceitual e refletir sobre a disputa entre projetos diferentes no que se refere à manipulação genética das sementes por meio do "PAA Sementes" e suas consequências. O horizonte temporal trabalhado se situa no contexto de ascensão das demandas sociais e políticas durante os governos do Partido dos Trabalhadores (PT - 2002 a 2015). Os dados referentes ao "PAA Sementes" ainda são escassos, por se tratar de uma recente política pública. A maior parte desses foram coletados a partir de fontes secundárias de órgãos federais, estaduais e municipais organizadas na web page "PAA Data". Sabe-se que essas informações ainda não são substanciais, mas procura-se utilizar esses dados como forma de testar as hipóteses levantadas. 
Este artigo está dividido em três partes. Inicialmente, apresentamos um framework conceitual que nos permite explorar o contencioso dos recursos genéticos a partir da concepção de fungibilidade do poder. $\mathrm{Na}$ sequência, discutimos a resistência camponesa ao controle das sementes e como isso tem repercutido no processo de disputa pelo Estado. Por último, exploramos a capacidade do "PAA Sementes" em promover o controle camponês de recursos genéticos ao possibilitar o acesso desses ao mercado institucional sob condições especiais.

Da geopolítica à biopolítica dos recursos genéticos no comércio internacional de grãos

Nesta seção do artigo buscamos apreciar a instrumentalização das técnicas de fabricação e mercantilização da vida (Rose, 2007) pela lógica do capital. Partimos do intuito inicial de que o uso da biotecnologia e das patentes genéticas legitimam a lógica biopolítica de fazer alguns viverem e deixar outros tantos morrerem (Foucault, 2003). Dessa forma, a expansão dos mecanismos biopolíticos para todos os domínios da vida biológica se caracteriza como um dos principais procedimentos de controle sobre a (re) produção da vida. Esse fenômeno implica diretamente na flexibilização das temporalidades e espacialidades dos instrumentos da artificialização das sementes enquanto commodity agrícola e a partir da revolução biotecnológica na agricultura como o cerne da disputa entre diversos atores.

Talvez um dos aspectos mais marcantes da sociedade de consumo contemporânea seja a contínua expansão da lógica do mercado a todas as dimensões da vida humana, incluindo a dimensão biológica da própria fabricação da vida (Rose, 2007), ou seja, ao domínio da biotecnologia. Nesse sentido, o poder na contemporaneidade não pode ser mais vislumbrado apenas pela dimensão da soberania territorial. Não foi por mera coincidência que os conceitos de geopolítica e biopolítica foram cunhados pelo autor germanófilo Rudolf Kjellen, o que de certa forma implicava em um sistema de análise em que o poder territorial poderia se fundir ao poder populacional e vice-versa. Autores como Ingram (2009) e Braun (2007) explicitam os mecanismos de fusão da geopolítica e da biopolítica. Dessa forma, a ideia do Estado Territorial não está dissociada da ideia do Estado Populacional, uma vez que Foucault (2003) afirmava que para fazer viver ou deixar morrer é necessária a organização de um arranjo 
espacial específico para lograr esse objetivo. Na perspectiva biopolítica ${ }^{1}$, o estado se estabelece enquanto ente gestor da vida por meio da ideia de governamentalidade que procura a auto disciplina dos seres sobre os corpos como também procura maximizar a vitalidade de uma população, tornando menos custoso o exercício do poder (Rabinow; Rose, 2006).

Nesse sentido, a lógica da disputa pelo mercado internacional parte da premissa de que a conquista de novos espaços de produção, circulação e consumo em todo o espaço global é de especial importância. No entanto, esses novos espaços não se referem apenas àqueles espaços tradicionais enquanto extensões territoriais. Uma vez que com o avanço da lógica capitalista e o descolamento das temporalidades da (re)produção e do consumo, o poder tornou-se exequível não apenas sobre extensões territoriais, mas também sobre a própria vida, em si mesma, enquanto espaço de disputa. Nesse sentido, partimos da ideia de que o controle sobre a vida é uma forma de controlar o tempo e nesse sentido a tradicional soberania territorial pode ser transformada em soberania sobre a vida a partir da apropriação de conhecimentos e saberes, uma vez que na reflexão foucaultiana saber é poder.

Harvey (1992), ao discorrer sobre a condição pós-moderna, fala do fenômeno da compressão do espaço pelo tempo. Nesse contexto, controlar a temporalidade da vida se caracteriza como um dos mecanismos de controle das dinâmicas territoriais pela flexibilização e manipulação da cotidianidade (everdayness) da qual Lefebvre (2004) tanto se refere em seus estudos. Isto é, controlar as dinâmicas espaço-temporais da vida a partir da instrumentalização da biotecnologia de acordo com a lógica da (re)produção do capital se apresenta como a mais nova face da biopolítica. Dessa forma, a biotecnologia se expandiu para todos os setores da fabricação da vida biológica e não apenas humana, forjando segundo Rose (2007) um mercado da vida a partir de uma bioeconomia que se estabelece pela manipulação biopolítica não mais ao nível da espécie, mas sim, intracelular. Segundo Rose (2007), a molecularização da vida trouxe um novo momento na história da biopolítica, no qual os

1 No sistema conceitual da biopolítica, existe para Foucault um diagrama bipolar em que um polo foca uma anatomo-política do corpo humano buscando maximizar suas forças e integra-las em sistemas eficientes. Já um segundo polo consiste em controles reguladores, uma biopolítica da população, enfocando nas espécias e no corpo, o corpo imbuído no mecanismo da vida. Para Pogrebinschi (2004, p. 197) há "um elemento em comum que transita entre o poder disciplinar e o biopoder, entre a disciplina e a regulamentação, e que possibilita a manutenção do equilíbrio entre a ordem disciplinar do corpo e a ordem aleatória da população". 
corpos são entendidos em termos da sua herança genética. Rose (2007), ainda assevera que essa não é a única forma em que a molecularização da vida foi apreendida, já que ela também se deu pela biopolítica global da biossegurança. Nessa perspectiva, Braun (2007) adverte que a principal resposta da segurança ao problema dos desconhecidos é o ato especulativo, isto é, ato de preempção. Nesta instância, toda forma de vida pode ser modificada a partir da manipulação dos genes enquanto building blocks da vida pluripotente (Dillon; Lobo-Guerrero, 2008), para fazer frente a algum risco possível à segurança.

Naturalmente, no mercado agrícola global, estratégias várias de poder se estabelecem e o mecanismo de compressão do espaço pelo tempo não seria único, uma vez que o processo oposto de compressão do tempo pela organização do espaço também é possível e evidentemente tratar-se-ia, nesse caso, de uma geopolítica. Neste trabalho nos interessamos essencialmente pelo mecanismo oposto, a instar, a manipulação das técnicas de fabricação da vida como forma de manipular as temporalidades de um dado lugar, e consequentemente, a espacialidade vivenciada no cotidiano. De certa forma, a manipulação genética de sementes enquanto vida em potencial permite a construção de outra espacialidade que não seria possível caso as sementes não fossem geneticamente modificadas para apresentar onticamente certas características.

Na agricultura capitalista, o cerne das estratégias de controle sobre a fabricação da vida gira em torno da manipulação genética das sementes. Manipular geneticamente as sementes, flexibilizando o tempo, seja pela aceleração ou pela paralisação dos processos de (re)produção da vida são essenciais para adaptar a temporalidade ecológica à temporalidade do capital (Gurvitch, 1964)represents the triumph of a super-relativism and a consequent empiricism)". (5. Assim, manipular o tempo da vida também implica em produzir múltiplos espaços de forma diversa daquelas até então possibilitadas pelas condições fisiográficas e tecnológicas. Partindo dessa premissa, pode-se dizer que o controle da fabricação da vida se estabelece enquanto um mecanismo de controle da produção do espaço seja pela aceleração ou retardamento do tempo de (re)produção da vida.

Castree (2001) aponta que a manipulação genética permite a produção de novas necessidades de consumo daqueles que a utilizam para a produção agrícola. Nessa perspectiva, o geógrafo britânico demonstra que empresas do agronegócio como a Monsanto, entre outras, tornam as 
sementes inférteis com a finalidade de obrigar os produtores a comprarem novas sementes ao invés de replantar parte daquelas que foram produzidas.

A manipulação genética também cria uma série de outras "inovações”, para não dizer obrigações, aos produtores rurais. Essencialmente, Whatmore (2002) explica como o uso do herbicida Roundup ${ }^{(\mathrm{R})}$ somente pode ser aplicado com sucesso nas sementes transgênicas produzidas pela Monsanto, caso contrário o referido produto produzirá um efeito deletério sobre o plantio efetuado com sementes de outras marcas.

Segundo o ETC Group (2015), o mercado de sementes, embora não seja o mais lucrativo, é aquele que comanda a cadeia do agronegócio, uma vez que a partir da transformação genética das sementes pode-se produzir inúmeras formas de novos produtos a serem necessariamente consumidos sob pena de gerar baixa produtiva ou mesmo tornar a produção inviável.

Outro mecanismo importante de controle sobre a vida se refere à patentização dos produtos a serem comercializados no mercado agrícola global. Sob a perspectiva do controle de qualidade, commodities agrícolas são padronizadas. Nesse aspecto, a obrigação da modificação genética das sementes como forma de atender ao padrão exigido pelo mercado agrícola global se estabelece como um mecanismo de legitimar o direito de propriedade intelectual das grandes empresas localizadas nos países desenvolvidos. Esse processo, por consequência, implica na perda da biodiversidade da produção agrícola especialmente nos países grandes exportadores de commodities.

Shiva (2001) chama atenção para a ideia de colonização da vida, utilizando uma analogia. Se no período colonial, grandes extensões de terras foram colonizadas pelas metrópoles por não terem natureza privada e assim consideradas como terra de ninguém (terra nullius), no período contemporâneo, o mesmo pode se dizer, segundo a autora, a respeito da biodiversidade e da vida em si, enquanto vida de ninguém (bio nullius). Uma vez que, em muitas circunstâncias os recursos biológicos não são privados, eles estão susceptíveis à apropriação de entes privados sob a justificativa de que suas propriedades foram patenteadas. Para a autora indiana, esse mecanismo se constitui em uma forma de biopirataria disfarçada.

Diante deste processo, camponeses têm se articulado e enquanto movimento social resistem a tal curso. Adiante, discutiremos a evolução da luta no campo ao incorporar tal pauta, bem como o Estado que, 
compreendido como um espaço de disputa por poder, tem sido mobilizado a agir.

\section{A resistência camponesa ao controle das sementes pelas grandes corporações}

Como apontado na seção anterior, uma das formas por meio das quais a agricultura capitalista mantém sua hegemonia na condução do modelo de desenvolvimento para o campo é o controle dos recursos genéticos, especialmente as sementes. Tal fato tem sido extremamente prejudicial para os camponeses, contribuindo para sua situação de subalternidade em relação às grandes corporações do agronegócio. Conforme Kloppenburg (2008), os camponeses têm perdido a soberania sobre as sementes, de tal modo que eles já não podem mais escolher quais dentre elas plantar e quais salvar. Isso acontece devido aos seguintes fatores:

[...], a indústria de sementes tem perseguido essas rotas - técnica e social - para os mais restritos acessos dos agricultores de sementes para confinar e aumentar um conjunto estreito de mecanismos de mercado. [...] Tanto as estruturas de governança nacionais quanto as internacionais - que são, instituições como a Organização Mundial do Comércio (OMC) e a Convenção da Diversidade Biológica (CDB), bem como as leis nacionais - têm sido usadas para a elaboração global de um conjunto de direitos de propriedade intelectual (DPI) baseados no princípio da exclusão. Por fazerem poupanças de sementes patenteadas ilegais, esses acordos são efetivamente prisões das práticas dos agricultores, bem como de suas sementes (Kloppenburg, 2008, não paginado, tradução nossa).

Portanto, devido ao acesso desigual às tecnologias, as sementes têm deixado de ser um bem social para se tornar propriedade de grandes corporações que investem grande gama de dinheiro para a realização de pesquisas de melhoramento genético. Cada vez mais tem sido evidente a sua mercantilização e instrumentalização para os interesses capitalistas. Na medida em que o direito de propriedade intelectual sobre as sementes é adquirido e exercido pelas grandes corporações, ocorre uma concentração de poder por parte delas, fato que implica negativamente na luta pela permanência na terra por parte dos camponeses.

Como pode ser observado na coletânea organizada por Carvalho (2003), para os camponeses as sementes possuem uma importância que vai além do seu aspecto mercantil, possuindo também valores culturais 
e espirituais. Por exemplo, o conhecimento sobre a correta utilização das sementes na produção agrícola é transmitido nas famílias camponesas majoritariamente de forma oral, passando de geração em geração. Isso indica que as sementes são elementos de grande importância na cosmovisão dos camponeses e não apenas um recurso produtivo. Tal afirmativa, reforça a clássica tese de Chayanov (1981) de que a agricultura de base familiar não pode ser interpretada por meio das leis capitalistas, pois ela não possui os lucros ampliados como objetivo principal e sim, sua própria reprodução. Essa cosmovisão se baseia em uma cotidianidade (everydayness) diversa daquela produzida pela lógica da (re)produção do capital.

Nesse contexto, o campesinato manifesta uma resistência às temporalidades tecnificadas da aceleração ou paralisação da (re)produção da vida. A biotecnologia em si mesmo não é perversa, porém o que a torna positiva ou negativa são as intencionalidades na sua utilização. Nesse sentido, as manipulações dos mecanismos de reprodução da vida pela lógica do capital são primordialmente utilizadas especialmente para a (re) produção em larga escala do capital. Exemplo disso pode ser verificado no fato de que a maior parte do comércio internacional de grãos é direcionado para alimentar animais, ao invés de ser direcionado às populações em situação de inanição. Assim, a manipulação dessa temporalidade também permite a construção de uma espacialidade diferente, uma vez que a partir da manipulação da temporalidade da (re)produção da vida pode-se alcançar a comercialização de produtos perecíveis na escala global pela manipulação genética dos mesmos. Naturalmente, a ampliação para a escala global visa a produção de mercadorias para principais mercados consumidores no exterior.

Essa intencionalidade apresenta-se fundamentalmente tanto para o Estado populacional, já que pela manipulação da vida produz-se maior quantidade de cultivos para alimentar a população local, quanto para a biopolítica global no sentido de aumentar a geração de energia do material biológico renovável para assegurar a vida em outros lugares. Segundo Rabinow e Rose (2006) na nova economia política da vitalidade os fluxos transnacionais de conhecimento, células, tecidos e propriedade intelectual estão associados a intensificações locais e são regulados por instituições transnacionais.

Em razão disso, a La Via Campesina - a principal coalizão de movimentos camponeses do mundo, reunindo 164 membros, os quais estão 
presentes em todos os continentes - tem qualificado o controle sobre as sementes como uma de suas principais bandeiras de luta. Na busca por construir e implementar um modelo de desenvolvimento para o campo que leve em consideração o modo de vida e produção dos camponeses e indígenas, ela tem destacado que as sementes devem ser pensadas como de importância fundamental.

No ano de 2002, durante a Cúpula Mundial de Alimentação, da Organização das Nações Unidas (ONU), a La Via Campesina decidiu implementar a campanha "Sementes: patrimônio do povo a serviço da humanidade”. Essa foi consolidada no Fórum Social Mundial, realizado em Porto Alegre, no ano de 2003. Constavam dentre os objetivos dessa campanha: i) possibilitar aos camponeses controlar suas próprias sementes "varietais" individualmente ou em comunidade; ii) garantir a produção de sementes de modo democrático e não como uma exclusividade das grandes corporações; iii) evitar a comercialização de sementes apenas pelo viés econômico e; iv) impedir a transmissão de sementes transgênicas (La Via Campesina, 2003).

Embasados nessa campanha, movimentos sociais do campo brasileiros que são vinculados à La Via Campesina também têm pontuado nos últimos anos a importância de lutar pelo controle da produção e distribuição das sementes. Suas ações podem ser definidas como de cunho contestatório ou então propositivo. Como exemplo da primeira pode ser citada a manifestação organizada pelo Movimento dos Trabalhadores Rurais Sem Terra (MST), o Movimento Camponês Popular (MCP), o Movimento das Mulheres Camponesas (MMC), o Movimento dos Atingidos por Barragens (MAB) e o Movimento dos Atingidos pela Mineração (MAM) na sede da empresa DuPont, em Catalão, no estado de Goiás, no dia 02 de outubro de 2015. Com tal ação, esses movimentos sociais do campo visavam evidenciar os perigos da produção e venda de sementes geneticamente modificadas. Como exemplo do segundo pode ser citada a criação de uma cartilha homônima à campanha efetivada pela Via Campesina pelo Movimento dos Pequenos Agricultores (MPA), na qual ele apresenta diversos procedimentos que podem ser adotados por seus membros para evitar o uso de sementes híbridas e privilegiar o uso de sementes crioulas (MPA, s/d)"title" : "Sementes: patrimlu00f4nio dos povos a servilu00e7o da humanidade", "type” : "article” \}, "uris" : [ "http://www.mendeley. com/documents/?uuid=f6ea055b-8c8a-4944-8a60-5adb3a7b6e5d”, “http:// 
www.mendeley.com/documents/?uuid=aab0b9e8-8f00-4623-9a1e7224e7d3055c"] \} ], "mendeley" : \{ “formattedCitation" : “(MOVIMENTO DOS PEQUENOS AGRICULTORES (MPA.

O que vale ressaltar a partir dessas experiências é que no Brasil, cada vez mais, a luta pela terra e na terra ganham maior amplitude. $\mathrm{O}$ objetivo não tem sido quase que exclusivamente o de superar o latifúndio por meio da criação de assentamentos rurais, como ocorria até o final da década de 1990. Atualmente, novos temas têm sido incorporados, como é o caso das sementes, devido ao fato de que a Questão Agrária é de caráter estrutural e ela só pode ser superada com a implantação de um modelo de desenvolvimento alternativo. Fundamentalmente, os movimentos sociais procuram mobilizar recursos políticos de forma a aproveitar oportunidades constituidas pela atuação do Estado ao fazer uso de um dispositivo da segurança (Tilly, 2008). Mais especificamente, pode-se citar um discurso de verdade sobre soberania dos recursos genéticos nacionais. Em um horizonte conjuntural, movimentos sociais do campo procuram capitalizar recursos políticos, o que de certa forma leva a um ponto de tensão nessa forma de alinhamento perverso entre o discurso de soberania nacional sobre os recursos genéticos e a ideia de controle coletivo dos mesmos pelos movimentos sociais.

Dentre os quadros dos movimentos sociais do campo ainda existem os que defendem que isso se dará por meio de um processo revolucionário que ocorrerá mediante a negação do Estado, seguindo uma perspectiva marxista ortodoxa. Contudo, nos últimos anos tem sido cada vez mais veemente a opção de pressionar o Estado, levando-o a implantar políticas públicas que não estejam presas ao modelo de agricultura previsto pelo agronegócio (Akram-Lodhi, 2015).

No caso do Brasil, isso contribuiu para que com a chegada de Luís Inácio Lula da Silva, do PT à Presidência da República, no ano de 2003, os movimentos sociais do campo vissem algumas de suas demandas por mudanças nos sistemas alimentares serem atendidas. Apesar de o agronegócio ter permanecido como hegemônico no campo, criou-se um ambiente institucional que possibilitou a implantação de políticas públicas para o campo com caráter emancipatório. Ou seja, como parte da conflitualidade que caracteriza a Questão Agrária brasileira atual, houve um acirramento da tensão pelo Estado entre o agronegócio e a agricultura camponesa (Barbosa Júnior; Coca, 2015). 
Para efeito do presente trabalho é importante ressaltar esse contexto porque a demanda dos movimentos sociais do campo pelo controle das sementes em oposição à transgenia acabou se materializando numa política pública, no caso o Programa de Aquisição de Alimentos (PAA), em sua modalidade "Sementes", como exploramos na seção seguinte.

\section{PAA Sementes como forma de equacionamento biopolítico da disputa pelos recursos genéticos}

Ainda em 2003, como parte do Programa Fome Zero (PFZ), o Governo Lula da Silva implementou o PAA, atendendo a uma antiga demanda de movimentos sociais do campo, especialmente os vinculados à Via Campesina (Muller, 2007). Essa política pública foi pensada para funcionar estruturalmente, atendendo a dois objetivos principais: i) a compra governamental de alimentos produzidos por camponeses que são identificados como tais mediante à sua Declaração de Aptidão (DAP) ao Programa Nacional de Fortalecimento da Agricultura Familiar (PRONAF) e; ii) a doação de parte desses produtos para pessoas em condição de vulnerabilidade social que são atendidas por entidades da rede socioassistencial como albergues, casas de recuperação de usuários de drogas, hospitais, escolas, creches, asilos e outros; visando, assim, atender ao Direito Humano à Alimentação Adequada (DHAA). De tal modo, o PAA se constitui como a única política de compras públicas de alimento do mundo que pontua os camponeses como grupo de produtores prioritários (De Schutter, 2014).

Com o passar do tempo, o PAA foi passando por modificações, sendo que atualmente, destacam-se dentre suas principais características: i) a preferência pela aquisição de produtos oriundos de associações e cooperativas que sejam exclusivamente ou majoritariamente geridos por mulheres, contribuindo com a superação do padrão patriarcal das relações sociais no campo (Coca, 2015; Siliprandi; Cintrão, 2014); ii) o pagamento de valores especiais para os produtos que sejam certificados como orgânicos ou agroecológicos, contribuindo com a sustentabilidade das práticas agrícolas e com a ingestão de alimentos de melhor qualidade por parte dos consumidores (Galindo; Sambuichi; Oliveira, 2014); iii) a compra de produtos diversificados e conforme a estação do ano, fato que contribui para o desenvolvimento da policultura nas unidades de produção dos proponentes (Coca, 2015) e outros. 
O PAA trabalha com seis modalidades: i) Compra da Agricultura Familiar para Doação Simultânea; ii) Formação de Estoques pela Agricultura Familiar; iii) Compra Direta da Agricultura Familiar; iv) Incentivo à Produção e Consumo de Leite; v) Compra Institucional e; vi) Aquisição de Sementes. Ele é gerido com recursos do Ministério do Desenvolvimento Social e Combate à Fome (MDS) e do Ministério do Desenvolvimento Agrário (MDA) e operacionalizado pela Companhia Nacional de Abastecimento (CONAB), que é vinculada ao Ministério da Agricultura, Pecuária e Abastecimento (MAPA).

Para efeito deste trabalho, vale ressaltar o caráter inovador da modalidade "Aquisição de Sementes", que foi implantada pelo Decreto 8.293, de 12 de agosto de 2014, que modificou o Decreto 7.775, de 04 de julho de 2012. Ela visa a compra pelo Governo Federal de sementes que não sejam geneticamente modificadas e sua doação para camponeses de baixa renda, ou seja, existe uma clara intenção de romper com a hegemonia das grandes corporações do agronegócio no controle dos recursos genéticos do campo.

Interessante notar as consequências espaço-temporais dessas iniciativas, uma vez que projetos dessa natureza preservam a manutenção das temporalidades do campo, especialmente, pela (re)produção de práticas que respeitam as temporalidades ecológicas. Ademais, na dimensão espacial, a iniciativa permitiria interligar espaços não conectados ao comércio internacional de grãos, criando assim uma relação de interdependência entre espaços fora do circuito internacional por meio de iniciativas regionais ou locais. Constitui-se assim um mecanismo de produção de uma economia paralela aos fluxos do comércio internacional.

No "PAA Sementes" os camponeses proponentes podem realizar vendas de até R 16.000 anuais. Contudo, eles devem estar organizados em cooperativas ou associações que possuam DAP Jurídica, sendo que essas entidades têm um limite anual de vendas de até $\mathrm{R} \$ 6$ milhões. Reconhecendo que desde 2014 tem sido possível aos camponeses participar de mais de uma modalidade do PAA, chega-se à conclusão de que anualmente eles podem ter uma renda de mais de R\$ 60 mil somente por meio dessa política pública, ou seja, percebe-se que o PAA tem um grande potencial de contribuir para a garantia e a melhoria de renda no campo.

Os camponeses beneficiários, aqueles que recebem a doação das sementes, devem possuir DAP de pessoa física. São dadas preferências aos que façam parte do Cadastro Único para Programas Sociais do Governo 
Federal (Cadastro Único) - um instrumento que visa identificar os brasileiros em condição de vulnerabilidade social. Devido à essa característica, o "PAA Sementes" tem também por função auxiliar no combate à miséria, que consiste num dos principais problemas do campo no Brasil.

Como pode ser observado no Quadro 01, já no ano de 2015 foram adquiridas sementes de milho e feijão. Como o feijão foi comercializado apenas na Bahia, seus dados são bem menos significativos do que os do milho, o qual, além dessa unidade federativa também foi comercializado no Paraná, em Santa Catarina e em São Paulo, de forma mais extensiva nos últimos dois. De tal modo, observa-se que o "PAA Sementes" ainda possui pouca representatividade nos estados brasileiros, estando concentrado especialmente no Centro-Sul do país. Em parte, isso pode ser explicado porque esses estados estão dentre aqueles onde os movimentos sociais do campo estão mais organizados por meio de cooperativas e associações que possuem forte capacidade de mobilização.

Quadro 01 - Desempenho do PAA Sementes no ano de 2015

\begin{tabular}{|c|c|c|c|c|}
\hline Estado & $\begin{array}{c}\text { Sementes de feijão } \\
\text { em } \mathbf{~ k g}\end{array}$ & $\begin{array}{c}\text { Sementes de feijão } \\
\text { em } \mathbf{R} \mathbf{\$}\end{array}$ & $\begin{array}{c}\text { Sementes de milho } \\
\text { em } \mathbf{~ k g}\end{array}$ & $\begin{array}{c}\text { Sementes de milho } \\
\text { em } \mathbf{R} \mathbf{\$}\end{array}$ \\
\hline Bahia & 250.000 & $2.445 .000,00$ & 199.500 & $70.000,00$ \\
\hline Paraná & Não consta & Não consta & 195.000 & $50.000,00$ \\
\hline Santa Catarina & Não consta & Não consta & 496.000 & $80.000,00$ \\
\hline São Paulo & Não consta & Não consta & 707.600 & $250.000,00$ \\
\hline TOTAL & $\mathbf{2 5 0 . 0 0 0}$ & $\mathbf{2 . 4 4 5 . 0 0 0 , 0 0}$ & $\mathbf{1 . 5 9 8 . 1 0 0}$ & $\mathbf{4 5 0 . 0 0 0 , 0 0}$ \\
\hline
\end{tabular}

Fonte: PAA Data, 2016. Org. Estevan L. F. Coca.

Chama atenção ainda o fato de que tal política pública prioriza a aquisição de sementes crioulas, as quais se caracterizam por serem produzidas, mantidas e selecionadas por meio de conhecimentos tradicionais. Geralmente, as sementes crioulas trazem um repertório de seleção natural que ultrapassa milhares de anos. A permanência delas denota que a agricultura camponesa tem tido um importante papel na conservação da biodiversidade (Carvalho, 2014; Scoones, 2009). Essa iniciativa propicia assim a valorização e o reconhecimento dos saberes e práticas tradicionais, o que de alguma maneira atua como um mecanismo de proteção da propriedade intelectual. Ademais, a iniciativa permite a manutenção da biodiversidade, uma vez que incentiva a produção de cultivos outros além dos padronizados para a finalidade de exportação enquanto commodity 
ao marcado global de grãos. Nesse sentido, o mecanismo permite a (re) produção de outras temporalidades, outros ritmos para além da necessária (re)produção do capital.

No entanto, esse alinhamento entre o interesse de controlar os recursos genéticos pelos movimentos sociais e a necessidade de assegurar a vitalidade por meio da geração de energia a partir do material biológico pelo estado, pode, em um primeiro momento, se confluir de maneira positiva, mas em um momento posterior pode engendrar a perda pelos movimentos sociais do controle dos recursos genéticos para os aparatos do Estado.

Assim, observa-se que por meio do "PAA Sementes", o mercado institucional tem contribuído para diminuir a hegemonia que as grandes corporações do agronegócio têm exercido sobre os recursos genéticos. Essa política pública rompe com os princípios do neoliberalismo, pois por meio dela o Estado interfere no mercado de sementes. Além da mercantilização das sementes, também é colocada em evidência sua importância ética, pois ela relaciona-se não só com as práticas agrícolas dos camponeses, mas também com o modelo de alimentação da população de maneira geral.

\section{Considerações finais}

É importante notar que por meio dessa política pública os camponeses podem manter o controle sobre a forma tradicional de agricultura e os alimentos oriundos desta. Isso os coloca em contraposição ao modelo agroexportador hegemônico no Brasil, contribuindo em menor medida para a conservação da agrobiodiversidade. Essa tensão existente entre intencionalidades diferentes, movimentos sociais e o Estado pelo controle, ou mesmo o uso de recursos genéticos remete à uma luta colonial (Crosby, 1986; Mazoyer; Roudart, 2006). Contudo, essa não se dá na tradicional via de ser colonizado por um país, mas sim, pelo colonizar do espaço de produção e do sistema alimentar perpetuados por empresas que não estão limitadas ou reguladas pelos Estados de modo que vêm transformando espaços públicos em empreendimentos privados.

Primeiramente, pode-se afirmar que o controle sobre os recursos genéticos se tornou um novo locus do exercício do poder. Fundamentalmente, o Estado procura fazer uso de um dispositivo da segurança como forma de assegurar a soberania sobre recursos genéticos e ao mesmo tempo intenta 
gerar maior produção de energia do material biológico a ser exportado enquanto capital econômico.

Em relação à premissa secundária, pode-se inferir que, embora tenha existido uma molecularização da vida, maior número de pesquisas precisam passar pelo escrutínio de duas observações. Na primeira delas, Braun (2007) se pergunta se realmente o corpo genético do século XXI se difere realmente do corpo eugênico e da clínica relatados por Foucault. Na posterior observação, embora seja indiscutível que se possa visualizar o fenômeno da vida em um nível submicroscópico, Braun (2007) questiona se a vida biológica do corpo é conceitualizada apenas em termos de uma herança genética e o seu melhoramento tecnológico, para não dizer genético.

Essa nova forma de colonialismo e de perda da soberania pôde, na perspectiva desse estudo, ser melhor compreendida pelo mecanismo de fungibilidade entre o poder territorial (geopolítica) e poder sobre a vida (biopolítica). Dessa forma, o mecanismo de controle sobre a temporalidade da vida a partir de técnicas de fabricação da vida torna possível a manipulação e a produção de novas espacialidades. Mais especificamente, o uso de sementes geneticamente modificadas para atender a mecanismo de padronização do mercado internacional, assim os usos de sementes crioulas possibilitam a construção de múltiplas espacialidades. É certo que as construções dessas múltiplas espaço-temporalidades atendem à intencionalidades divergentes e conflitantes. Resta, em parte, ao Estado produzir mecanismo para equilibrar e equacionar a dinâmica entre esses dois projetos. Preliminarmente, pode-se dizer que o PAA se apresenta como um desses mecanismos.

\section{Referências}

AKRAM-LODHI, A. H. Accelerating towards food sovereignty. Third World Quarterly, v. 36, n. 3, p. 563-583, 2015.

BARBOSA JÚNIOR, R. C.; COCA, E. L. DE F. Conflitos entre o campesinato e o agronegócio no Brasil: os planos-safra 2015-2016. Eutopía: Revista de Desarrollo Económico Territorial, v. 8, p. 13-27, 2015.

BRAUN, B. Biopolitics and the molecularization of life. Cultural Geographies, v. 14, n. 1, p. 6-28, 2007.

CARVALHO, H. M. DE. O camponês, guardião da agrobiodiversidade. Boletim DATALUTA, n. 1, 2014. 
CARVALHO, H. M. Sementes: patrimônio do povo a serviço da humanidade. São Paulo: Expressão Popular, 2003.

CASTREE, N. Marxism, Capitalism, and the Production of Nature. In: CASTREE, N.; BRAUN, B. (Eds.). . Social Nature. 1. ed. Malden: Blackwell Publishing, 2001. p. 189-207.

CHAYANOV, A. Sobre a teoria dos sistemas econômicos não capitalistas. In: SILVA, J. G. DA; STOLCKE, V. (Eds.). A Questão Agrária. São Paulo: Brasiliense, 1981. p. 133-164.

COCA, E. L. DE F. O Programa de Aquisição de Alimentos ( PAA ) como uma política pública emancipatória no território Cantuquiriguaçu-PR. Revista NERA, n. 26, p. 165-182, 2015.

CROSBY, A. W. Imperialismo ecológico: a expansão biológica da Europa 9001900. Cambridge: Cambridge University Press, 1986.

DE SCHUTTER, O. The Power of Procurement. Roma: [s.n.] , 2014.

DILLON, M. G.; LOBO-GUERRERO, L. Biopolitics of security in the 21st century: An Introduction. Review of International Studies, v. 34, p. 265-292, 2008.

ETC GROUP. Mega-Mergers in the Global Agricultural Inputs Sector: Threats to Food Security \& Climate Resilience. Ottawa: [s.n.].

FAO. Women - users, preservers and managers of agrobiodiversity. Rome: [s.n.], 1999.

FOOD AND AGRICULTURE ORGANIZATION OF THE UNITED NATIONS (FAO). Las compras públicas a la agricultura familiar y la seguridad alimentaria y nutricional en América Latina y el Caribe. Santiago: Food and Agriculture Organization of the United Nations (FAO), 2015.

FOUCAULT, M. "Society Must Be Defended": Lectures a the Collège de France, 1975-76. New York: Picador, 2003.

GAliNDO, E. P.; SAMBUICHI, R. R.; OliVEIRA, M. A. C. DE. Compras de produtos agroecológicos e orgânicos da agricultura familiar pelo Programa de Aquisição de Alimentos. In: MINISTÉRIO DO DESENVOLVIMENTO SOCIAL E COMBATE À FOME (MDS) (Ed.). PAA: 10 anos de aquisição de alimentos. Brasília: Secretaria Nacional de Segurança Alimentar e Nutricional/Secretaria de Avaliação e Gestão da Informação, 2014. p. 184-207.

GURVITCH, G. The spectrum of social time. Dordrecht: D. Reidel Publishing Company, 1964.

HARVEY, D. The Condition of Postmodernity: An Enquiry into the Origins of Cultural Change. 4. ed. Cambridge: Blackwell Publishing, 1992. v. 20

INGRAM, A. The Geopolitics of Disease. Geography Compass, v. 3, n. 6, p. 20842097, 2009.

KLOPPENBURG, J. Seeds, Sovereignty, and the Via Campesina: Plants, Property, and the Promise of Open Source Biology. Workshop on Food Soveriegnty: Theory, Praxis and Power, p. 26, 2008. 
LA VIA CAMPESINA. Sementes: patrimônio do povo a serviço da humanidade. Temporalis, n. 24, p. 352, 2003.

LEFEBVRE, H. Rhythmanalysis: space, time, and everyday life. London and New York: Continuum, 2004.

MAZOYER, M.; ROUDART, L. A History of World Agriculture: From the Neolithic Age to the Current Crisis. New York: Monthly Press Review, 2006.

MOVIMENTO DOS PEQUENOS AGRICULTORES (MPA). Sementes: patrimônio dos povos a serviço da humanidade Laranjeiras do Sul, [s.d.].

MULLER, A. L. A construção das políticas públicas para a agricultura familiar no Brasil: o caso do Programa de Aquisição de Alimentos. [s.l.] Universidade Federal do Rio Grande do Sul, 2007.

POGREBINSCHI, T. Foucault, para além do poder disciplinar e do biopoder. Lua Nova: Revista de Cultura e Política, n. 63, p. 180-201, 2004.

RABINOW, P.; ROSE, N. Biopower Today. Biosciences, v. 1, n. 2, p. 195-217, 2006.

ROSE, N. Molecular Politics, Somatic Ethics, and the Spirit of Biocapital. Social Theory $\&$ Health, v. 5, n. 1, p. 3-29, 2007.

SCOONES, I. Livelihoods perspectives and rural development. Journal of Peasant Studies, v. 36, n. 1, p. 171-196, 2009.

SHIVA, V. Protect or Plunder: Understanding Intellectual Property Rights. London: Zed Books Ltd., 2001.

SILIPRANDI, E.; CINTRÃO, R. As mulheres rurais e a diversidade de produtos no Programa de Aquisição de Alimentos. In: MINISTÉRIO DO DESENVOLVIMENTO SOCIAL E COMBATE À FOME (MDS) (Ed.). PAA: 10 anos de aquisição de alimentos. Brasília: Secretaria Nacional de Segurança Alimentar e Nutricional/Secretaria de Avaliação e Gestão da Informação, 2014. p. 114-151.

TILLY, C. Contentious Performances. 1. ed. Cambridge: Cambridge University Press, 2008.

WHATMORE, S. Hybrid Geographies: Natures Cultures Spaces. 1. ed. London: SAGE Publications Ltd, 2002.

\section{Reconhecimentos}

O primeiro e terceiro autor estão situados dentro do projeto Cerrado na encruzilhada entre o Espaço da (in)segurança e da Integração Nacional financiado pela Fundação de Amparo à Pesquisa do Estado de Goiás (FAPEG). O segundo tem bolsa de doutorado da Fundação de Amparo à Pesquisa do Estado de São Paulo (FAPESP). Gostaríamos de agradecer os professores Denis Castilho e Francisco da Mata Machado Tavares por seus valiosos comentários, em versões preliminares deste texto. 
Matheus Hoffmann Pfrimer - Possui graduação em Direito pela Universidade Católica de Goiás e Geografia pela Universidade de Federal de Goiás. Mestrado em Relações Internacionais e Integração Europeia pela Universidade de Liège (Bélgica). É Doutor e Pós-doutor em Geografia Política pela Universidade de São Paulo. Atualmente é professor do curso de Relações Internacionais da Universidade Federal de Goiás.

Estevan Leopoldo de Freitas Coca- Possui Graduação e Mestrado em Geografia pela Universidade Estadual Paulista. Atualmente é Doutorando em Geografia na Faculdade de Ciências e Tecnologia da Universidade Estadual Paulista.

Ricardo César Barbosa Júnior-Graduando em Relações Internacionais pela Universidade Federal de Goiás e Graduando em Direito pela Pontifícia Universidade Católica de Goiás.

Recebido para publicação em 3 de fevereiro de 2016

Aceito para publicação em 28 de março de 2016

Contribuição de cada autor no desenvolvimento do artigo

Todos os autores ofereceram substanciais contribuições científicas e intelectuais ao estudo. As tarefas de concepção e design do estudo, preparação e redação do manuscrito, bem como, revisão crítica foram desenvolvidas em grupo. O primeiro autor ficou especialmente responsável pelo desenvolvimento teórico-conceitual; o segundo autor, pela aquisição de dados e suas interpretação e análise; e o terceiro, pelos procedimentos técnicos e tradução do artigo. 